

\section{As juventudes e os sentidos do ensino médio em Palmas, TO, Brasil}

\section{Los jóvenes y los sentidos de la enseñanza media en Palmas, TO, Brasil \\ Youth and the Meanings of Secondary Education in Palmas, TO, Brazil}

Carolina Machado Rocha Busch Pereira*

\begin{abstract}
Resumo
A pesquisa se propõe ao debate sobre as relações entre juventudes e escola, problematizando o lugar que a escola ocupa na construção das relações sócio territoriais das juventudes. Partindo do entendimento de que a análise das práticas espaciais cotidianas, das culturas juvenis e das territorialidades é considerada relevante e bastante pertinente para uma discussão pela Geografia, é que buscasse realizar esta pesquisa, que investiga o modo como as juventudes constroem uma experiência no cotidiano escolar das escolas de ensino médio e a perspectiva geográfica de ensino a partir do uso de diferentes linguagens. A pesquisa buscará analisar as relações entre espaço geográfico e arte e possibilitar o desenvolvimento de um conjunto de atividades para pensar criticamente o espaço geográfico a partir do ensino e sua relação com a juventude.
\end{abstract}

\section{Palavras-chave}

cidade; cultura; adolescência.

* Universidade Federal do Tocantins. 


\section{Resumen}

La investigación tiene como objetivo debatir sobre la relación entre juventud y escuela, cuestionando el lugar que esta última ocupa en la construcción de las relaciones sociales territoriales de los jóvenes. Con base en el entendimiento de que el análisis de las prácticas espaciales cotidianas de las culturas juveniles y su territorialidad es relevante para la discusión geográfica, la investigación pretende comprender el modo en que los jóvenes construyen su experiencia en la cotidianidad escolar de las escuelas secundarias y, asimismo, incentivar la enseñanza geográfica a partir del uso de diferentes lenguajes. La investigación buscará analizar las relaciones entre el espacio geográfico y el arte para permitir, con ello, el desarrollo de un conjunto de actividades que inviten al pensamiento crítico sobre el espacio partiendo de una enseñanza relacionada con la juventud.

\section{Abstract}

The purpose of this investigation is to discuss the relationship between youth and school, questioning the place occupied by the latter in the construction of the territorial social relations of young men and women. Based on the understanding that the analysis of the daily spatial practices of youth cultures and their territoriality is relevant to geographical discussion, the investigation aims to understand the way that young people build their experience in the daily school life in high schools. It also seeks to encourage geographical education based on the use of different languages. Thus, the research will seek to analyze the relationships between geographical space and art in order to allow the development of a set of activities that promote the critical thinking about space, based on a youth-related type of teaching.

\section{Palabras clave}

ciudad; cultura; adolescencia.

\section{Keywords}

city; culture; adolescence. 


\section{Introdução}

O tema da juventude tem tomado corpo no Brasil de forma bastante intensa nos últimos anos, ampliando e diversificando os focos anteriormente existentes e colocando novas questões e desafios para a construção de diagnósticos e ferramentas de trabalho para quem atua em ações e iniciativas dirigidas aos jovens.

Há, no Brasil, uma diversidade de visões a respeito da juventude e diferentes modos pelos quais se definem os sujeitos. Apesar da grande variedade, é certo que os conceitos de adolescência e juventude correspondem a uma construção social, histórica, cultural e relacional, que através das diferentes épocas e processos históricos e sociais vieram adquirindo denotações e delimitações diferentes: "La juventud y la vejez no están dadas, sino que se construyen socialmente en la lucha entre jóvenes y viejos" (Bourdieu, 2000, p.164).

Desta forma, a juventude é tomada neste presente texto introdutório da pesquisa, como categoria histórica e social que para ser compreendida necessita ser considerada em suas múltiplas dimensões. Juventude, no singular, expressa uma condição geracional ou populacional; no plural, juventudes, situam-se os sujeitos em face da heterogeneidade de classe, gênero, cor, credo, enfim, da diversidade de condições em que os jovens produzem suas identidades. Nessa perspectiva, entende-se que a identidade juvenil não é dada simplesmente pela idade biológica ou psicológica, mas configura-se a partir de um processo contínuo de transformação individual e coletiva (Carrano, 2000).

O que significa afirmar, em grande parte, que juventude é uma categoria socialmente construída e, portanto, presente na ordem social e não na natural. Daí sua mutabilidade ao longo da história. A juventude é, portanto, uma representação simbólica fabricada dos grupos sociais.

Segundo Abrantes (2003), os jovens não vão simplesmente à escola: apropriam-se dela, atribuem-lhe sentidos e são transformados por ela. Se parte deles sente o processo de escolaridade como uma imposição, e até mesmo uma violência, a que muitos resistem ou até abandonam; para outros, esse processo é um suporte fundamental na construção do percurso de vida e do projeto de consolidação identitária. Em qualquer dos casos, a escola constitui hoje uma das instituições fundamentais em torno das quais os jovens estruturam as suas práticas e discursos, os seus trajetos e projetos, consolidação suas identidades e aprimoram suas histórias e geografias.

Ao falar de juventudes Cavalcanti (2013) alerta que é

Necessário admitir sua diversidade, no que diz respeito às práticas, ao conteúdo de suas representações, à sua inserção/ pertencimento social, ao gênero, a raças e etnias. Sendo assim, é melhor falar em juventudes, e conceber os alunos, então, nas múltiplas dimensões de um mesmo ser social. (p.79).

A motivação da pesquisa foi sendo construída pela problemática derivada das seguintes questões: Quem são os jovens que chegam ao Ensino Médio em Palmas? Quais são seus desejos expectativas? Existe uma cultura própria da juventude? Ou há juventudes e, assim, diferentes expressões culturais juvenis? Como os jovens vê em e vivem no espaço escolar? Como se apropriam do território a partir do uso e das práticas espaciais?

As práticas espaciais decorrem das atividades realizadas pelos sujeitos nas suas relações com o mundo a partir das relações construídas em atividades educativas, relações familiares, práticas de lazer e religiosas, redes de amizades, na utilização de espaços públicos e privados, dentre outras atividades que compões uma complexa rede de possibilidades.

Para pensar sobre as distintas juventudes em Palmas, TO, cabe refletir sobre o espaço da escola e de que maneira os jovens se relacionam com o ensino em geral e com a Geografia em particular.

\section{Localização e caracterização da área de estudo}

A pesquisa está sendo desenvolvida no município de Palmas, capital do estado do Tocantis (compreendido pela cidade de Palmas, distrito Buritirana e distrito Taquaruçu), junto a três escolas de ensino médio da rede estadual.

Palmas é considerada uma cidade do século XX por ter sido criada em 20 de maio de 1989, pouco tempo depois da criação do estado do Tocantinspela, Constituição Federal de 1988. Uma cidade completamente planejada, já que a cidade nasceu e foi projetada desde o início para ser a capital do estado do Tocantins, sendo também a mais nova capital estadual do país. 0 município caracteriza-se também por ter a melhor qualidade de vida entre as capitais e municípios da região norte do Brasil. 0 crescimento de Palmas foi demasiado grande durante a década de 1990. Em 1991, a cidade tinha uma população de 24.261 habitantes e no ano de 2000, a cidade já contava com 130.528 habitantes (Instituto Brasileiro de Geografia e Estatística - IBGE, 2015). Sua urbanização também cresceu nos últimos anos, Palmas teve um crescimento econômico de 8,7\%, maior do que o índice nacional e do Tocantins (IBGE, 2015).

Palmas é a capital brasileira que apresentou, entre 2000 e 2010, a maior taxa média de crescimento anual de população, segundo dados do Censo Demográfico 2010 (IBGE, 2010). 


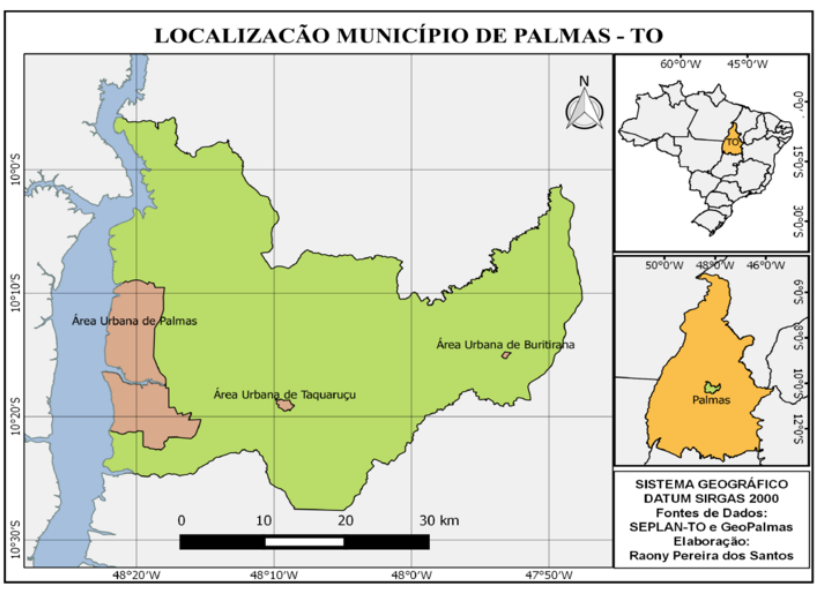

Figura 1. Mapa de localização de área da pesquisa. Fonte: elaboração própria.

\section{Os caminhos metodológicos da pesquisa}

O estudo está sendo desenvolvido no município de Palmas que possui população estimada em 272.726 habitantes dos quais $81 \%$ residem na área urbana, conforme dados do Instituto Brasileiro de Geografia e Estatística (2015).

A população jovem do município, entre 15 e 19 anos, consiste em 23.512 habitantes (IBGE, 2015). Em relação às escolas, o levantamento, realizado em fevereiro de 2016, contabilizou 35 escolas com Ensino Médio regular, sendo 15 da rede privada, 19 escolas da rede estadual e 1 escola pública federal (Ministério da Educação [MEC], 2015). A rede formada por estas 35 unidades de ensino médio atende 13.982 alunos matriculados no ensino médio (MEC, 2015), sendo 11.481 alunos matriculados no ensino médio da rede pública estadual, 1.693 na rede privada e 808 atendidos pela escola federal. Das 19 escolas estaduais de ensino médio, 13 são escolas em área urbana e 6 em área rural.

Considerando o número de escolas presentes no município de Palmas, iniciamos a pesquisa com 4 escolas estaduais, sendo 3 da área urbana e 1 da área rural. $\mathrm{Na}$ área urbana a escolha foi determinada pelo acesso e autorização para realizar a pesquisa. Elegemos uma escola de tempo integral (ESN) localizada na porção norte da cidade, região periférica com média de 36.2 alunos por turma, com um total de 600 alunos matriculados (SEDUC, 2016). A segunda escola localizada na região central de Palmas (EsC), e a terceira na porção sul da cidade (EsS), são escolas que possuem uma estrutura organizacional melhor que a escola da região norte e onde os indicadores de evasão e distorção idade-série são menores, assim como a média de alunos por turma. A escola da região central (EsC) possui 19.3 alunos por turma com um total de 504 alunos matriculados. E a escola da região sul (EsS) possui 20.4 alunos por turma com um total de 330 alunos matriculados. Na escola rural (EsR), a média de alunos por turma é de 22.1 alunos por turma com um total de 104 alunos matriculados.

Da totalidade (1.538 alunos), após o contato com as escolas, professores e alunos, a pesquisa delimitou o universo de participantes que ocorreu tanto por adesão e interesse dos alunos como também pela capacidade de acompanhamento da pesquisadora. Assim, a pesquisa acompanha atualmente 232 alunos conforme tabela 1.

Tabela 1. Total de alunos participantes da Pesquisa.

\begin{tabular}{|l|c|c|}
\hline Unidades & $\begin{array}{c}\text { Total de alunos } \\
\text { participantes da pesquisa }\end{array}$ & $\begin{array}{c}\text { Total de alunos } \\
\text { matriculados no ensino } \\
\text { médio }\end{array}$ \\
\hline EsR & 32 & 104 \\
\hline EsS & 63 & 330 \\
\hline EsC & 83 & 504 \\
\hline EsN & 54 & 600 \\
\hline Total & 232 & 1.538 \\
\hline
\end{tabular}

Fonte: elaboração própria.

Decidiu-se por estudar escolas de regiões e naturezas institucionais distintas com o intuito de abranger jovens com percursos e situações socioeconômicas diferentes, a fim de garantir que o conjunto de informantes fosse diversificado e, assim, reunir múltiplas realidades, possibilitando a apreensão de semelhanças e divergências entre uma geração presente nas escolas.

A pesquisa foi iniciada em fevereiro de 2016 e com um planejamento de execução para 3 anos. A metodologia da pesquisa está dividida em três momentos, a saber:

a) Investigações iniciais, revisão bibliográfica e definição da metodologia com escolha das técnicas de coleta de dados e montagem dos instrumentos.

b) O campo escolar: observação participante, realização de entrevistas, levantamento de dados e aplicação dos questionários.

c) Sistematização dos dados coletados com reflexão e análise.

A metodologia não antecede a pesquisa, mas antes é construída a luz da problemática, desta forma o primeiro momento da pesquisa exigiu um esforço de revisão de bibliografia e de definição do caminho metodológico.

Zanten (2004) orienta os primeiros passos da pesquisa qualitativa em educação alertando que uma pesquisa não se realiza com uma visita em um colégio em um dia. A validade de uma pesquisa em educação que 
envolve colégios, escolas ou centros de formação repousa no encontro disciplinar e sistematizado que só pode ocorrer com um período superior a um (1) ano escolar.

Nessa mesma perspectiva, Wolcott (apud Lüdke \& André, 1986, p. 14) faz uma discussão acerca dos vários critérios para o uso da etnografia na área de educação e defende que o trabalho de campo deve durar pelo menos um ano escolar. A abordagem etnográfica combina vários métodos de coleta na pesquisa qualitativa e apresenta uma grande quantidade de dados primários, uma vez que o pesquisador deve realizar a maior parte do trabalho de campo pessoalmente.

$\mathrm{Na}$ aproximação com a pesquisa qualitativa, o desdobramento natural foi compreender a natureza da pesquisa qualitativa e as diferentes matrizes de coletas de dados que nela repousam para então elaborar os instrumentos. Durante este primeiro momento, enquanto estudávamos e definíamos a estrutura metodológica, foram realizadas primeiras visitas nas escolas para apresentar o projeto à direção e professores de Geografia e começar a estabelecer os vínculos necessários para o desenvolvimento.

\section{A pesquisa qualitativa}

A pesquisa qualitativa emerge como abordagem capaz de promover não só as possibilidades de interpretação, mas, sobretudo de propiciar a formulação das questões para a investigação. Os investigadores que tomam o ambiente de educação como objeto de pesquisa, entendendo que nesse lugar o processo das relações humanas é dinâmico, interativo e interpretativo, devem construir seu arcabouço metodológico alicerçado pelas técnicas qualitativas (Lüdke \& André, 1986). Segundo Prus (apud Moreira, 2002), as pessoas interpretam seu mundo, compartilhando o seu modo de ver com outros que, por sua vez, também interpretam.

Para as autoras Lüdke e André (1986), o que vai determinar a escolha da metodologia é a natureza do problema. Para que a realidade complexa, que caracteriza a escola, seja estudada com rigor científico necessitará dos subsídios encontrados na vertente qualitativa de pesquisa. Isso pelo fato de haver uma atenção com o preparo do planejamento, com o controle da pesquisa, com a escolha do objeto, dentre outras características anteriormente apresentadas.

As contribuições desse tipo de investigação estão presentes na sua capacidade de compreensão dos fenômenos relacionados à escola, uma vez que retrata toda a riqueza do dia-a-dia escolar. Assim, os estudos qualitativos são importantes por proporcionar a real relação entre teoria e prática, oferecendo ferramentas eficazes para a interpretação das questões educacionais. Para Luna (2000), em uma pesquisa de cunho qualitativo, a escolha da técnica de análise tem a ver com a formulação do problema a ser investigado. Assim, a teoria deve tanto sugerir perguntas como indicar possibilidades de interpretação, servindo de referencial para os resultados que vão sendo observados.

Minayo (1994) diz que a pesquisa qualitativa responde a questões particulares, enfoca um nível de realidade que não pode ser quantificado e trabalha com um universo de múltiplos significados, motivos, aspirações, crenças, valores e atitudes. A autora defende que qualquer investigação social deveria contemplar uma característica básica de seu objeto, que é o aspecto qualitativo.

\section{Observação participante}

O pesquisador qualitativo pauta seus estudos na interpretação do mundo real, preocupando-se com o caráter hermenêutico na tarefa de pesquisar sobre a experiência vivida dos seres humanos, neste caso os alunos do ensino médio, da cidade de Palmas, TO. Moreira (2002) elucida que os objetos de estudo das ciências humanas e sociais são as pessoas e suas atividades, considerando-os "não apenas agentes interpretativos de seus mundos, mas também compartilham suas interpretações à medida que interagem com outros e refletem sobre suas experiências no curso de suas atividades cotidianas" (p.50).

Na observação participante, como técnica de pesquisa qualitativa, os investigadores emergem no mundo dos sujeitos observados, orientados por compreender o comportamento dos sujeitos, suas próprias situações e como constroem a realidade em que atuam. Segundo Moreira (2002), a observação participante é conceituada como sendo "uma estratégia de campo que combina ao mesmo tempo a participação ativa com os sujeitos, a observação intensiva em ambientes naturais, entrevistas abertas informais e análise documental” (p.52). 0 autor explica que essa técnica foi impulsionada por um grupo de estúdios da Escola de Chicago, que fizeram pesquisas de campo, estudando e observando grupos sociais da zona urbana, na década de 1920. Ainda segundo Moreira (2002), o principal produto dessa observação participante é o que se conhece por relato etnográfico, entendido como "relatos detalhados do que acontece no dia-a-dia das vidas dos sujeitos e é derivado das notas de campo tomadas pelo pesquisador" (p.52).

Considerando a problemática que orienta a pesquisa e a definição pela pesquisa qualitativa com observação participante, iniciamos o percurso de definir os instrumentos para coleta de dados, que ao final se traduziram em dois momentos distintos, um roteiro de entrevista e um questionário, ambos aplicados durante a observação participante que ocorre uma vez por semana em cada uma das escolas da pesquisa. A observação é feita a partir das aulas de Geografia e prolonga-se pelo período de intervalo entre as aulas. 


\section{Resultados preliminares e reflexão teórica sobre juventudes e educação}

Delors (1996) em relatório internacional sobre a educação para o século XXI, destaca que a escola básica passou a desempenhar um papel fundamental na preparação de cidadãos para uma participação ativa, uma vez que os princípios democráticos expandiram-se por todo o mundo. Assim, para ele, a experimentação de práticas escolares pelos alunos, como jornais da escola, criação de parlamentos dos alunos, elaboração de regulamentos da comunidade escolar, simulação do funcionamento de instituições democráticas, exercício de resoluções não-violentas de conflitos, tendem a reforçar a aprendizagem da democracia. No entanto, "sendo a educação para a cidadania e democracia, por excelência, uma educação que não se limita ao espaço e tempo da educação formal, é preciso implicar diretamente nela as famílias e outros membros da comunidade" (Delors, 1996, p.60).

Na defesa de uma educação cívica que contemple, simultaneamente, a adesão a valores, a aquisição de conhecimentos e a aprendizagem de práticas de participação na vida pública, Delors (1996) recomenda que a educação, desde a infância e ao longo de toda a vida, desenvolva no aluno a capacidade crítica que lhe permita ter um pensamento livre e uma ação autônoma. Trata-se, portanto, da exigência de um ensino que seja um processo de construção da capacidade de discernimento, capaz de propiciar ao aluno a conciliação entre o exercício dos direitos individuais, fundados na liberdade pública e a prática dos deveres e da responsabilidade em relação aos outros e às comunidades a que pertencem. (Delors, 1996).

No contexto brasileiro, a reformulação do ensino médio instituída pela Lei de Diretrizes e Bases da Educação Nacional (LDBEN), de 1996, e posteriormente regulamentada pelas Diretrizes do Conselho Nacional de Educação e pelos Parâmetros Curriculares Nacionais, ao deixar de ter como foco a educação para o ensino superior ou profissionalizante, acentua, especificamente, a necessidade e responsabilidade de complementação da educação básica. Isto significa "preparar para a vida", "qualificar para a cidadania" e "capacitar para o aprendizado permanente", seja em relação ao prosseguimento dos estudos, seja em relação ao mundo do trabalho.

Mais do que reproduzir dados, denominar classificações ou identificar símbolos, está formando para a vida, num mundo como o atual, de tão rápidas transformações e de tão difíceis contradições, significa saber se informar, se comunicar, argumentar, compreender e agir, enfrentar problemas de qualquer natureza, participar socialmente, de forma prática e solidária, ser capaz de elaborar críticas ou propostas e, especialmente, adquirir uma atitude de permanente aprendizado. (MEC, 2000, p.09).
Ora, tal formação exige um método de ensino no qual o aluno tenha condições efetivas de comunicação, argumentação, resolução de problemas, participação social e cidadã, de modo a saber propor e fazer escolhas. Mas como a escola, lócus de criação de espaços de aprendizagem, está sendo compreendida pelos jovens?

A primeira questão apresentada aos jovens das escolas participantes da pesquisa foi: Qual o sentido da escola na sua vida? A questão foi feita aberta para que eles pudessem responder a partir do sentido que conferem a escola. Nas respostas encontramos respostas das mais variadas, entretanto um conjunto prevalece nas opções apresentadas:

- A escola é um direito que tenho

- Para conseguir um emprego

- O sentido de socializar e conhecer pessoas

- Encontrar amigos

- Estudar e me preparar para o futuro

Interessante observar que o sentido dado a escola pouco ou quase nada se relaciona com o ensino superior. Apesar de muitos jovens, em um momento posterior, manifestarem o desejo de "ter uma carreira"; "conseguir boa pontuação no ENEM"; "entrar em uma universidade" quando questionados sobre o que desejam ao sair da escola, quando questionados sobre o sentido da escola o ensino superior aparece em poucas respostas.

Por outro lado, a manifestação de muitos alunos ao fato da escola ser um direito indica a presença do reconhecimento dos direitos civis, o que pode apontar para um trabalho de cidadania e educação que tem sido construído nos anos anteriores pelas escolas.

Quando questionado sobre a obrigação de ir à escola apenas 12,5\% confirmaram a obrigatoriedade os demais, um número expressivo, disseram que vão à escola por querem. Outra questão levantada foi sobre o interesse dos jovens pelas disciplinas oferecidas na escola. Quando perguntado se eles se interessam por alguma disciplina em particular. $77,4 \%$ dos jovens afirmaram ter interesse especial em uma disciplina, e neste rol, a Geografia aparece como a primeira opção de $28,87 \%$ dos jovens em geral conforme dados da tabela 2. 
Tabela 2. Identificação do interesse dos alunos pela Geografia.

\begin{tabular}{|l|c|c|}
\hline Unidades & $\begin{array}{c}\text { A Geografia é a disciplina } \\
\text { que mais gosto }\end{array}$ & Total de alunos \\
\hline EsR & $9=28,12 \%$ & 32 \\
\hline ESS & $13=20,63 \%$ & 63 \\
\hline EsC & $24=28,91 \%$ & 83 \\
\hline EsN & $21=38,88 \%$ & 54 \\
\hline Total & $67=28,87 \%$ & 232 \\
\hline
\end{tabular}

Fonte: elaboração própria.

Refletir sobre o papel social da escola a partir da ótica das juventudes é, sem dúvida, uma tarefa difícil, visto que abarca, dentre outras características, desde noções socialmente construídas e confirmadas ao longo da história até outras que encontram um melhor significa dono campo dos desejos individuais, implicando diretamente, portanto, a observação ou o atendimento de anseios específicos.

Moura (2013) afirma que

não se trata mais de manter a escola como um local apenas do conhecimento, isto é, no domínio dos conteúdos, mas de idealizar e oferecer uma escola que valorizará formas de organização nas quais prevaleçam a integração social, a convivência entre diferentes, o compartilhamento de culturas, o encontro, a solidariedade entre as pessoas e sua formação, além de um ensino que possibilite a todos se apropriarem dos conhecimentos produzidos ao longo da história, de modo que cada indivíduo em particular possa objetivar-se enquanto um ser humano pleno, histórico e social (p.712).

Sobre a função da escola, Libâneo (2012) afirma que a escola deve ajudar os alunos a desenvolver suas capacidades intelectuais e cognitivas frente a um conjunto de problemas sociais existentes no mundo hoje e que afetam a juventude. Por conseguinte, os professores ao ensinar devem organizar os conteúdos levando em conta as características dos alunos, uma vez que a escola não detém mais o monopólio do saber, como ocorria no passado. Os alunos chegam às escolas com conhecimentos adquiridos sob outras formas de aprendizado e em outros espaços.

\section{Considerações finais}

A pesquisa encontra-se em andamento e, portanto, apresenta dados preliminares de uma coleta que ainda não se encerrou, contudo, a observação de campo tem apontado que os jovens, apesar de todas as dificuldades que vivenciam nesse contexto, vêem a escola como um instrumento importante para tornar realidade seus projetos, fazendo com que nela permaneçam. Encontrar entre os jovens o interesse por ir à escola e estudar como livre escolha e não mais como uma imposição é um dado relevante e importante uma vez que sinaliza que a escola ainda possui reconhecimento para estes jovens como espaço importante de aprendizagem.

Assim, os jovens compõem sentidos positivos e se motivam em relação à escola, não obstante, sabem apontar as deficiências e fragilidades que estão presentes na escola, sem, com isso, desvalorizá-la. Com uma expectativa mais ampla em torno da escola, os jovens têm como principal sentido para estarem e permanecerem na escola aquilo que a educação burguesa imprimiu às sociedades industriais desde o século XIX, uma melhor configuração para o trabalho, algo necessário para manter a expectativa/possibilidade de um bom emprego, seja ou não por meio do acesso ao Ensino Superior.

É importante conhecer e refletir sobre quais são as funções da escola para que possam ser traçados com clareza os objetivos pretendidos na formação dos alunos. A escola é concebida como uma instituição que pode ser transformadora e como um instrumento de modificação da sociedade atual. E, também, deveria ser um espaço onde todos tivessem igual acesso ao conhecimento científico. $O$ acesso à escola, bem como a permanência dos alunos nela, tem que ser uma das funções prioritárias dos Governos, e a sociedade deve buscar a garantia desses direitos. Melhorar a escola é o primeiro passo de um longo caminho que ainda temos pela frente para transformar e melhorar a sociedade. 


\section{Referências}

Abrantes, P. (2003). Identidades juvenis e dinâmicas de escolaridade. Revista Sociologia, Problemas e Práticas, (41), 93-115.

Bourdieu, P. (2000). Cuestiones de sociología. Madrid: Istmo.

Carrano, P. (2000). Juventudes: as identidades são múltiplas. Movimento: Revista de Educação, (1), 11-27.

Cavalcanti, L. (2013). Jovens escolares e a cidade: concepções e práticas espaciais urbanas cotidianas. Caderno Prudentino de Geografia, (35), 74-86.

Delors, J. (Org.). (1996). Educação um tesouro a descobrir: relatório para UNESCO da comissão internacional sobre educação para o século XXI. Cortez: UNESCO.

Instituto Brasileiro de Geografia e Estatística [IBGE] (2015). Cidades. Disponível em http://cod.ibge.gov.br

Libâneo, J. (2012). O dualismo perverso da escola pública brasileira: escola do conhecimento para os ricos, escola do acolhimento social para os pobres. Educação e Pesquisa, 38(1), 13-28.

Lüdke, M. e André, M. E. D. A. (1986). Pesquisa em educação: abordagens qualitativas. São Paulo: EPU.

Luna, S. V. (2000) O falso conflito entre tendências metodológicas. In: I. Fazenda. (Org.). Metodologia da pesquisa educacional. (6 ed., pp 21-33). São Paulo: Cortez.

Minayo, M. C. S. (1994) Ciência, técnica e arte: o desafio da pesquisa social.In: M. C. Minayo \& S. F. Deslandes (Orgs.). Pesquisa social: teoria, método e criatividade. (18. ed., pp. 9-29). Petrópolis: Vozes.

Moreira, D. (2002). O método fenomenológico na pesquisa. São Paulo: Pioneira Thomson.

Moura, D. H. (2013). Ensino Médio Integrado: subsunção aos interessesdo capital ou travessia para a formação humana integral? Educação e Pesquisa, 39, (3), pp. 705-720.

Ministério da Educação [MEC]. (2000). Parâmetros Curriculares Nacionais: Ensino Médio. Secretaria de Educação Média e Tecnológica. Brasília: Autor. Disponível em: http://portal.mec.gov.br/seb/arquivos/pdf/blegais.pdf. Acesso em: 30 de setembro de 2010,

Ministério da Educação [MEC] (2015). Censo Educacional 2015. Instituto Nacional de Estudos e Pesquisas Educacionais. Disponível em http://cidades.ibge.gov.br Acesso em 27 de junho de 2016.

Zanten, A. Van. (2004). Pesquisa qualitativa em educação: pertinência, validez e generalização. Perspectiva, 22, (1), pp. $25-45$. 